\title{
Erratum to: Generalized n-tupled fixed point theorems for nonlinear contractions
}

\author{
Mohammad Imdad $^{1}$ - Anupam Sharma ${ }^{1}$. \\ K. P. R. $\mathbf{R a o}^{2}$
}

Published online: 19 October 2015

(C) African Mathematical Union and Springer-Verlag Berlin Heidelberg 2015

\section{Erratum to: Afr. Mat. (2015) 26:443-455 DOI 10.1007/s13370-013-0217-8}

Recently, we have proved some results on the existence and uniqueness of $2 n$-tupled fixed points for nonlinear $(\Phi, \Psi)$ contractions enjoying the mixed monotone property in partially ordered complete metric spaces but failed to mention the evenness of $n$. In this errata, we point out such corrections.

The list of corrections noted in the original paper runs as follows:

(i) At page 444, line (-16):

The statement " $n$ stands for any natural number greater than 1 " must be replaced by " $n$ stands for an even natural number".

That is, our results are true merely for even natural numbers but not for an arbitrary natural number as noted in [1].

(ii) At page 447, line 8:

The statement "... sequences $\left\{x_{m}^{1}\right\},\left\{x_{m}^{2}\right\},\left\{x_{m}^{3}\right\}, \ldots,\left\{x_{m}^{n}\right\} \in X$ ” must be replaced by “... sequences $\left\{x_{m}^{1}\right\},\left\{x_{m}^{2}\right\},\left\{x_{m}^{3}\right\}, \ldots,\left\{x_{m}^{n}\right\} \subset X$ ”.

(iii) At page 453, line 16:

The online version of the original article can be found under doi:10.1007/s13370-013-0217-8.

\section{Mohammad Imdad \\ mhimdad@yahoo.co.in \\ Anupam Sharma \\ annusharma241@gmail.com}

K. P. R. Rao

kprrao2004@yahoo.com

1 Department of Mathematics, Aligarh Muslim University, Aligarh 202 002, India

2 Department of Mathematics, Acharya Nagarjuna University,

Nagarjuna Nagar 522 510, Andhra Pradesh, India 
The statement "For any fixed integer $n>1$ " must be replaced by "For any fixed even natural number".

(iv) At page 453, line 19:

$$
\frac{x^{1}-x^{2}+x^{3}-x^{4}+\cdots+x^{n-1}+(-1)^{n+1} x^{n}}{2 n}, \quad \forall x^{1}, x^{2}, \ldots, x^{n} \in X,
$$

must be replaced by

$$
\frac{x^{1}-x^{2}+x^{3}-x^{4}+\cdots+x^{n-1}-x^{n}}{2 n}, \forall x^{1}, x^{2}, \ldots, x^{n} \in X .
$$

(v) At page 453, in lines 24, 25 and 26:

“. $\cdots+x^{n-1}+(-1)^{n+1} x^{n} "$ must be replaced by “ $\cdots+x^{n-1}-x^{n} "$

(vi) At page 453, in lines 24, 25 and 26:

“. $\ldots+y^{n-1}+(-1)^{n+1} y^{n} "$ must be replaced by “ $\cdots+y^{n-1}-y^{n} "$.

(vii) At page 453, in line 27:

“. $\cdots+(-1)^{n+1}\left(x^{n}-y^{n}\right)$ ” must be replaced by “. $\ldots-\left(x^{n}-y^{n}\right)$ ”.

(viii) At page 454, in Ref. [12], the title of the article "On $n$-tupled coincidence and common fixed points results in metric spaces" must be replaced by "On $n$-tupled coincidence point results in metric spaces".

\section{Reference}

1. Imdad, M., Soliman, A.H., Choudhury, B.S., Das, P.: On $n$-tupled coincidence point results in metric spaces. J. Oper. (2013). Article ID 532867. 